\title{
Scanning Electron Microscopy of Toxoplasma gondii
}

\author{
By A. S. KLAINER,* J. L. KRAHENBUHL AND J. S. REMINGTON \\ Division of Infectious Diseases, Department of Medicine, Ohio State University, Columbus, \\ Ohio, 43210; Division of Allergy, Immunology and Infectious Diseases, Palo Alto Medical \\ Research Foundation, and Division of Infectious Diseases, Department of Medicine, Stanford \\ University School of Medicine, Palo Alto, California, U.S.A.
}

(Received 3I August 1972)

SUMMAR Y

Scanning electron microscopy of intact fixed trophozoites of Toxoplasma gondii showed typical crescent-shaped organisms with clear polar structures. Examination of living organisms exposed to mouse peritoneal macrophages and L-cells and then fixed suggested that phagocytosis is one method of entry of the parasite into both phagocytic cells and those usually considered non-phagocytic. Antibody and accessory factor collapsed the organisms; irregular vacuoles appeared on their surfaces and cytoplasmic contents were extruded.

\section{INTRODUCTION}

Although Nicolle \& Manceaux (1908) published the first morphologic descriptions of Toxoplasma in 1908, it was not until I 954 that its ultrastructure was further defined by examination of thin sections with the transmission electron microscope (TEM) (Gustafson, Agar \& Cramer, 1954). This report presents details of the surface morphology of intact, fixed organisms as viewed with the scanning electron microscope (SEM). Since the SEM allows visualization of surface phenomena at high magnification in three-dimensional perspective, these studies were expanded to investigate the effects of exposing the parasite to macrophages, L-cells, and specific antibody.

\section{METHODS}

Macrophage cultures. Peritoneal macrophages were obtained from normal Swiss mice weighing 22 to $25 \mathrm{~g}$ as described previcusly (Ruskin, McIntosh \& Remington, 1969). Macrophages were counted with a haemocytometer and seeded $\left(2 \times 10^{6}\right)$ in $0.5 \mathrm{ml}$ medium on circular coverslips ( $18 \mathrm{~mm}$ diam.) resting in loosely stoppered shell vials (2 I mm diam.). Medium 199 (GIBCO, Berkeley, California, U.S.A.) containing $20 \%$ foetal calf serum and antibiotics ( 100 units penicillin, $100 \mu \mathrm{g}$ streptomycin $/ \mathrm{ml}$ ) was used for all cell cultures. Cells were washed with $0.15 \mathrm{M}$-saline. After $2 \mathrm{~h}$ of incubation at $37^{\circ} \mathrm{C}\left(5 \% \mathrm{CO}_{2}\right), 2 \mathrm{ml}$ medium was added, and incubation continued overnight.

Preparation of toxoplasma. Peritoneal fluid, containing intracellular and extracellular trophozoites of the RH strain, was collected from 3-day infected mice and placed in heparinated Hanks's balanced salt solution (HBSS). Intercellular parasites were released by forcing the suspension through a 27 -gauge needle. Unlysed peritoneal cells were removed by filtration through sintered glass filters as previously described (Remington, Bloomfield, Russell, \&

* Present address: Division of Infectious Diseases, West Virginia University Medical Center, Morgantown, Wcst Virginia, 26506, U.S.A. 


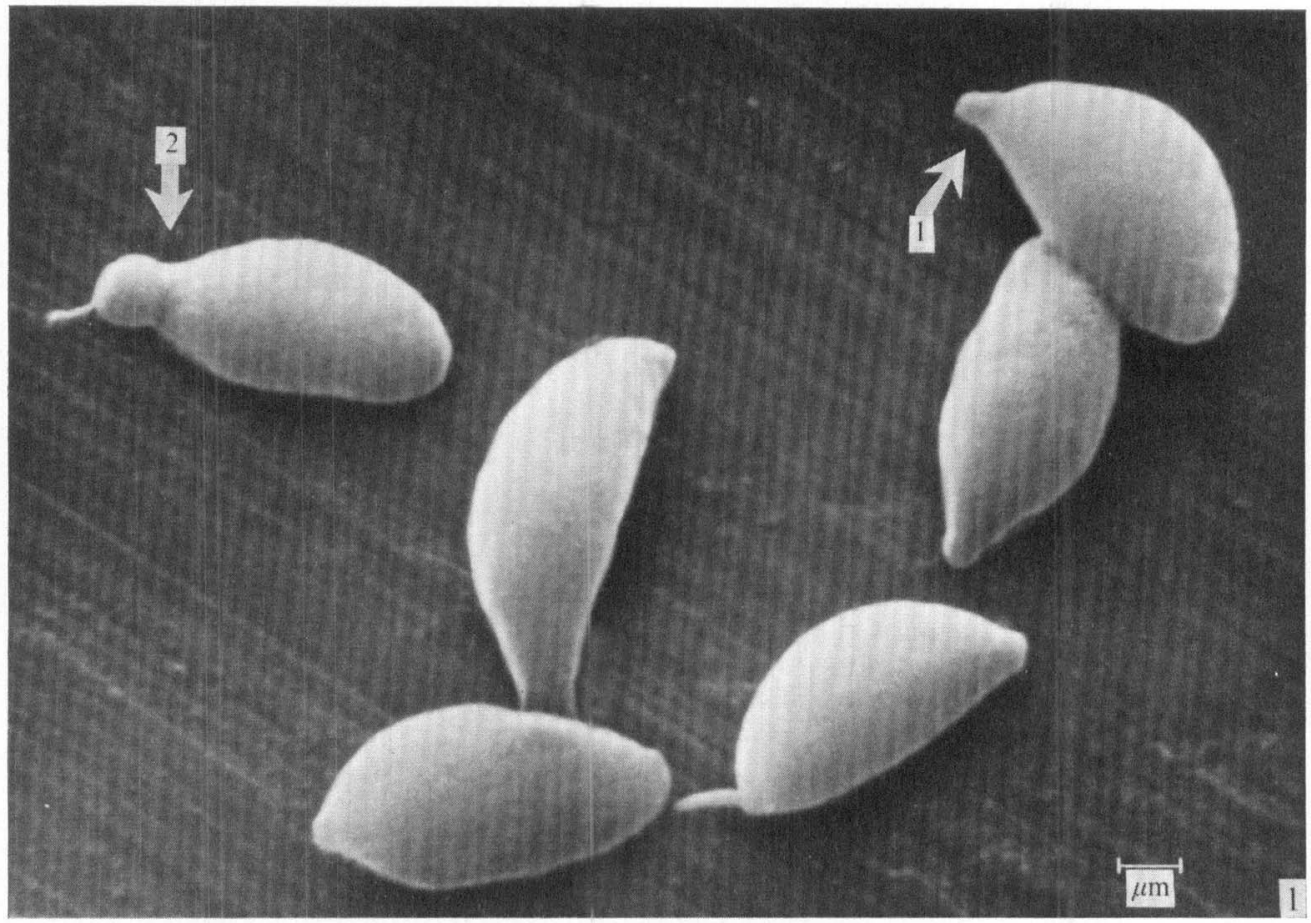

All Figures are scanning electron micrographs of Toxoplasma gondii.

Fig. 1. Trophozoites. Arrow I demonstrates an organism in which the polar ring surrounds the conoid at the top causing it to resemble a small truncated cone; arrow 2 demonstrates a trophozoite in which the polar ring is more proximal causing the conoid to be larger and nipple-shaped.

Robinson, I970). The resulting pure suspension of Toxoplasma trophozoites was washed twice $(600 \mathrm{~g})$, resuspended in medium and counted in a haemocytometer.

Macrophage monolayers were infected with $5 \times 10^{6}$ Toxoplasma in $0.5 \mathrm{ml}$ medium and immediately reincubated. Following infection of the monolayers at zero time, representative coverslips were fixed with $0.25 \%$ phosphate-buffered glutaraldehyde $(\mathrm{pH} \mathrm{7.2)} \mathrm{2,} \mathrm{4,} \mathrm{6,} \mathrm{8,} \mathrm{I} \mathrm{2,}$ and 16 min after infection.

L-cell cultures. L-cells were maintained by bi-weekly passage. Coverslips in shell vials were seeded with $3 \times 10^{5} \mathrm{~L}$-cells and incubated for $24 \mathrm{~h}$. The monolayers were then washed with HBSS and challenged with either $\mathrm{I} \times 10^{6}$ or $5 \times 10^{6}$ filtered $\mathrm{RH}$ Toxoplasma trophozoites suspended in $0.5 \mathrm{ml}$ medium. Sample coverslips were fixed with $0.25 \%$ glutaraldehyde $5, \mathrm{I} 5$, 25,45 , and $60 \mathrm{~min}$ after challenge.

Antibody-killed Toxoplasma organisms. Purified Toxoplasma trophozoites were washed ( $180 \mathrm{~g}$ ) in HBSS containing $20 \%$ human accessory factor (Feldman, 1956). Sedimented organisms were resuspended in $80 \%$ accessory factor $20 \%$ HBSS. A $2.5 \mathrm{ml} \mathrm{sample}$ of this suspension was added to either an equal amount of $0.15 \mathrm{M}-\mathrm{NaCl}$ (control) or $2.5 \mathrm{ml}$ of a $\mathrm{I}: 4$ dilution of a human serum having a Sabin-Feldman dye test titre of I/IO24. After I $h$ of incubation at $37^{\circ} \mathrm{C}$, these suspensions were centrifuged ( $\mathrm{I} 80 \mathrm{~g}$ ) and resuspended in $\mathrm{I} \cdot 0 \mathrm{ml}$ of $0.25 \%$ glutaraldehyde.

Preparation of specimens for SEM. After fixation in glutaraldehyde, preparations were washed three times by flooding with large volumes of sterile, distilled, demineralized water. 


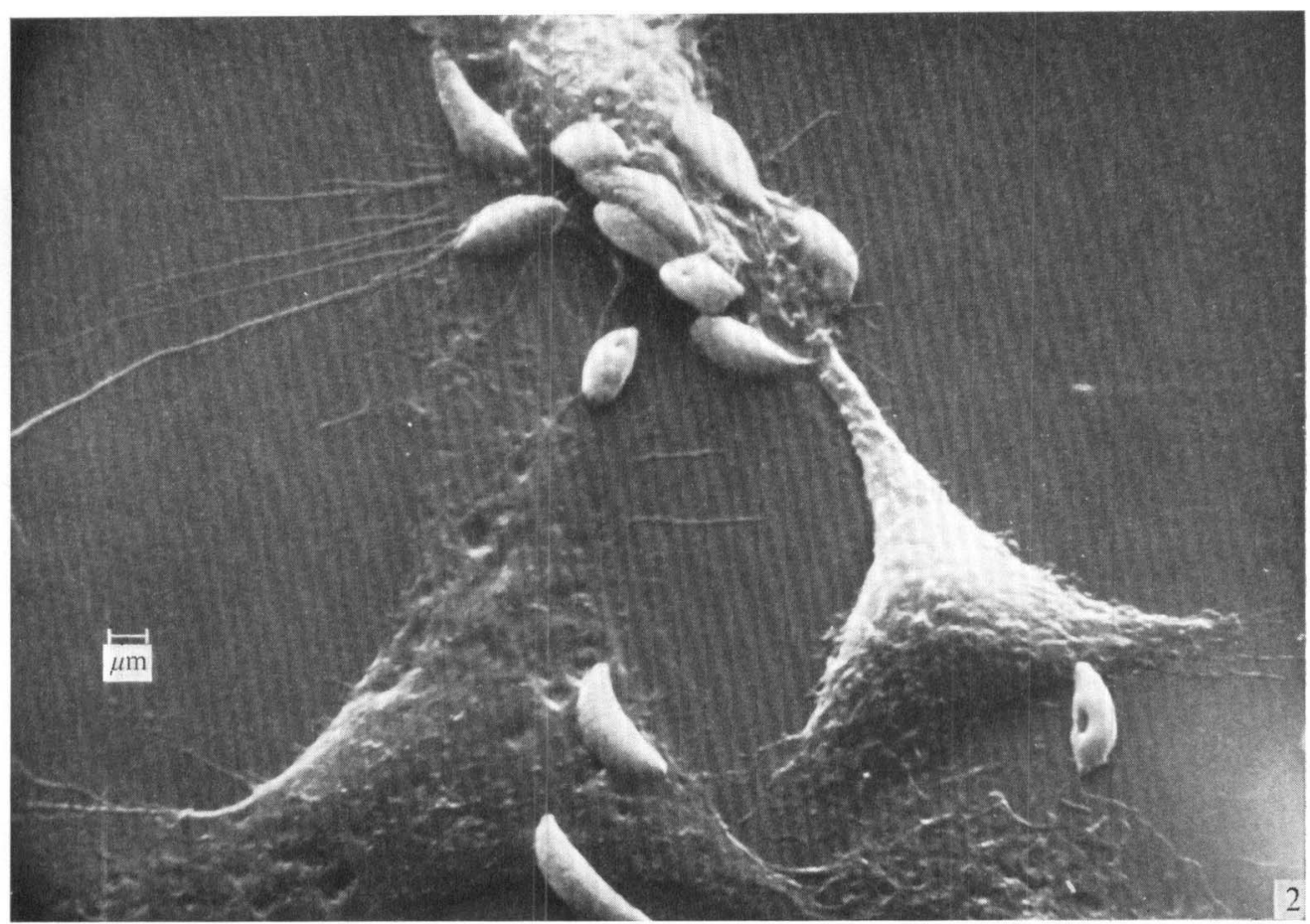

Fig. 2. Attachment of trophozoites to the surface of mouse peritoneal macrophages.

Further treatment of specimens has been previously reported (Klainer \& Betsch, 1970). Specimens were examined with a Cambridge Mark II Stereoscan Electron Microscope (Cambridge Scientific Instruments Ltd, London) operating at $20 \mathrm{kV}$. The specimen stage angle was kept constant at $26^{\circ}$. Micrographs were obtained with Polaroid sheet film (type $55 \mathrm{P} / \mathrm{N}$, Polaroid Corporation, Waltham, Massachusetts, U.S.A.).

\section{RESULTS}

Fig. I. illustrates trophozoites of Toxoplasma gondii as viewed with the SEM. The organisms are crescent-shaped and possess two differently structured poles; one is more round, the other is more pointed and probably the site of the conoid. The shape of the conoid appears to vary, and when the polar ring surrounds the conoid at the top, the latter appears smaller and resembles more closely a small truncated cone (arrow I); when the polar ring appears to be more proximal, the conoid is nipple-shaped and larger (arrow 2). The surface of the trophozoites is smooth, regular and homogeneous.

Fig. 2 to 4 illustrate the organism in relationship to mouse peritoneal macrophages. Fig. 2 demonstrates attachment of trophozoites to the macrophage surface, whereas Fig. 3 shows presumably intracellular organisms. Fig. 4 illustrates pseudopods of a macrophage above and around a trophozoite consistent with surface phagocytosis.

When L-cells were exposed to the organism, several types of surface relationship were observed: (i) penetration or phagocytosis with no specific role for the conoid since either end of the organism was observed to enter the L-cell first (Fig. 5); (ii) trapping of the organism between the L-cell membrane and the substrate typical of 


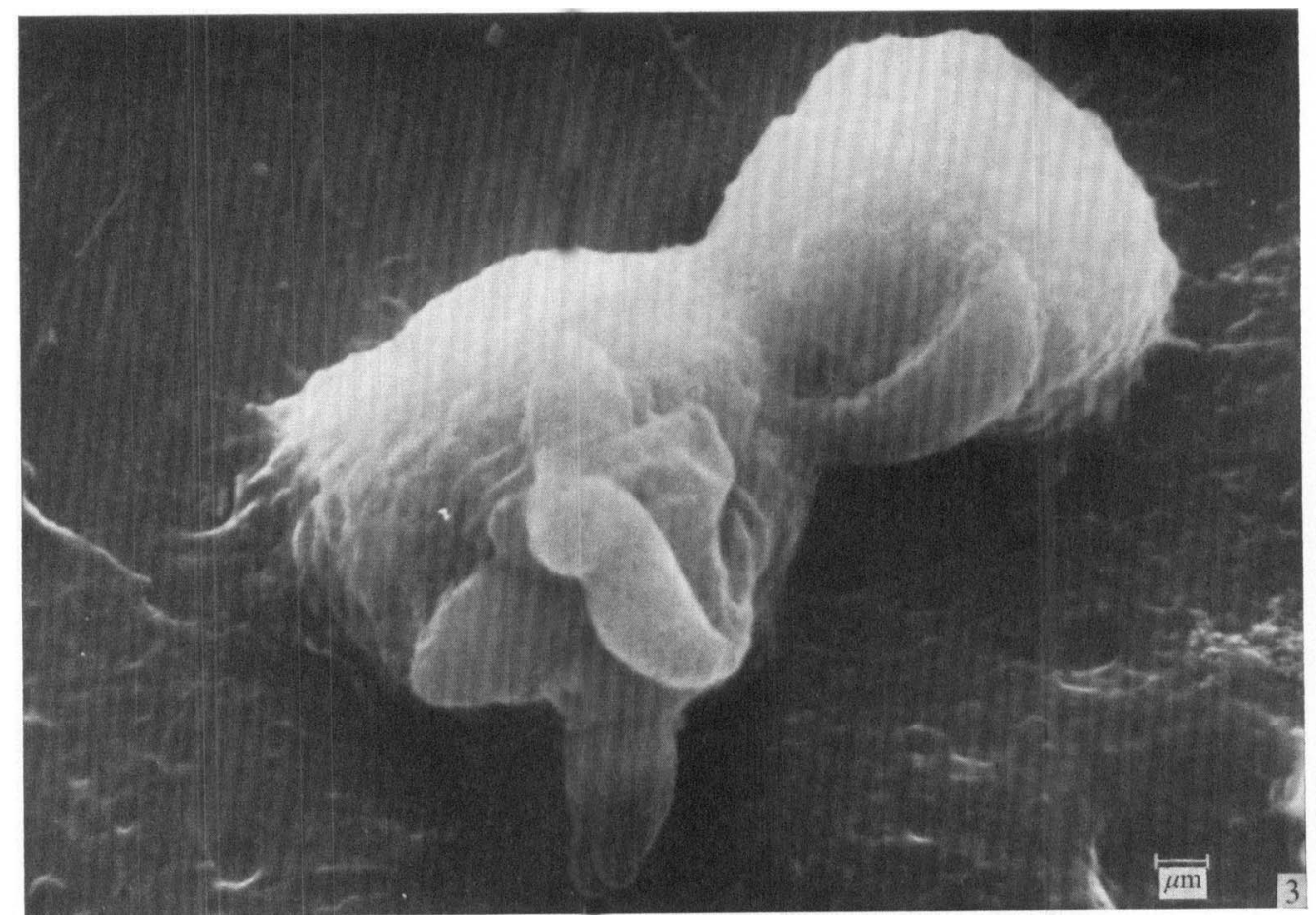

Fig. 3. Trophozoites seen beneath the surface of mouse peritoneal macrophages.

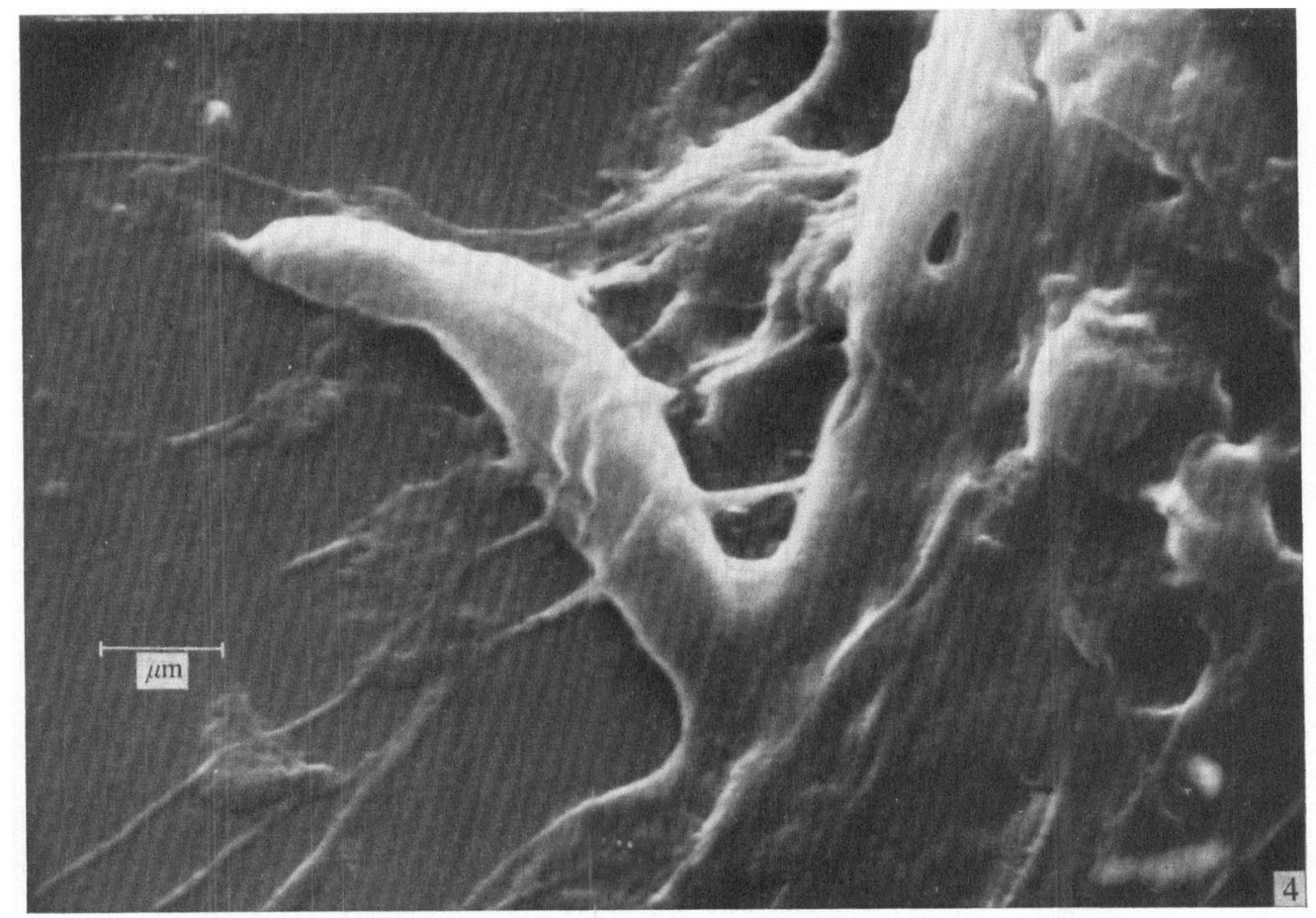

Fig. 4. Pseudopods of a mouse peritoneal macrophage above and around a trophozoite. 


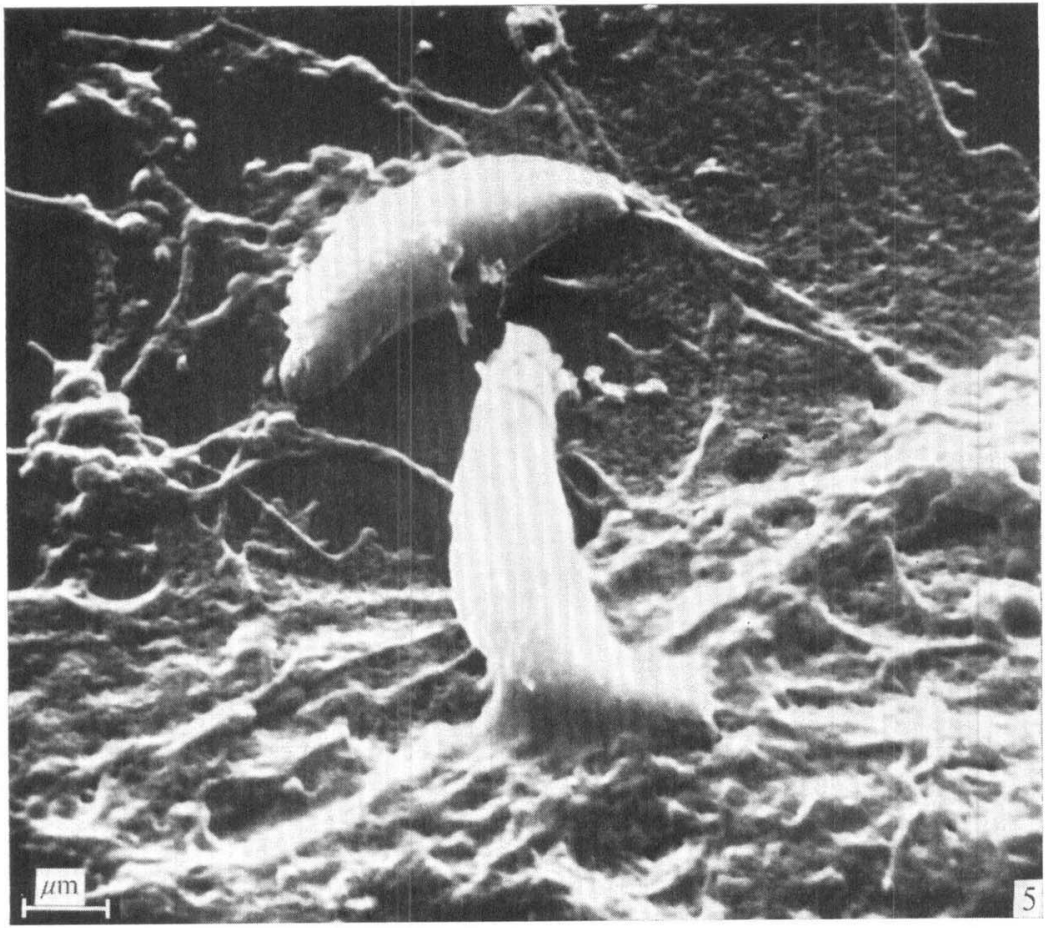

Fig. 5. A trophozoite appearing to penetrate the surface of an L-cell.

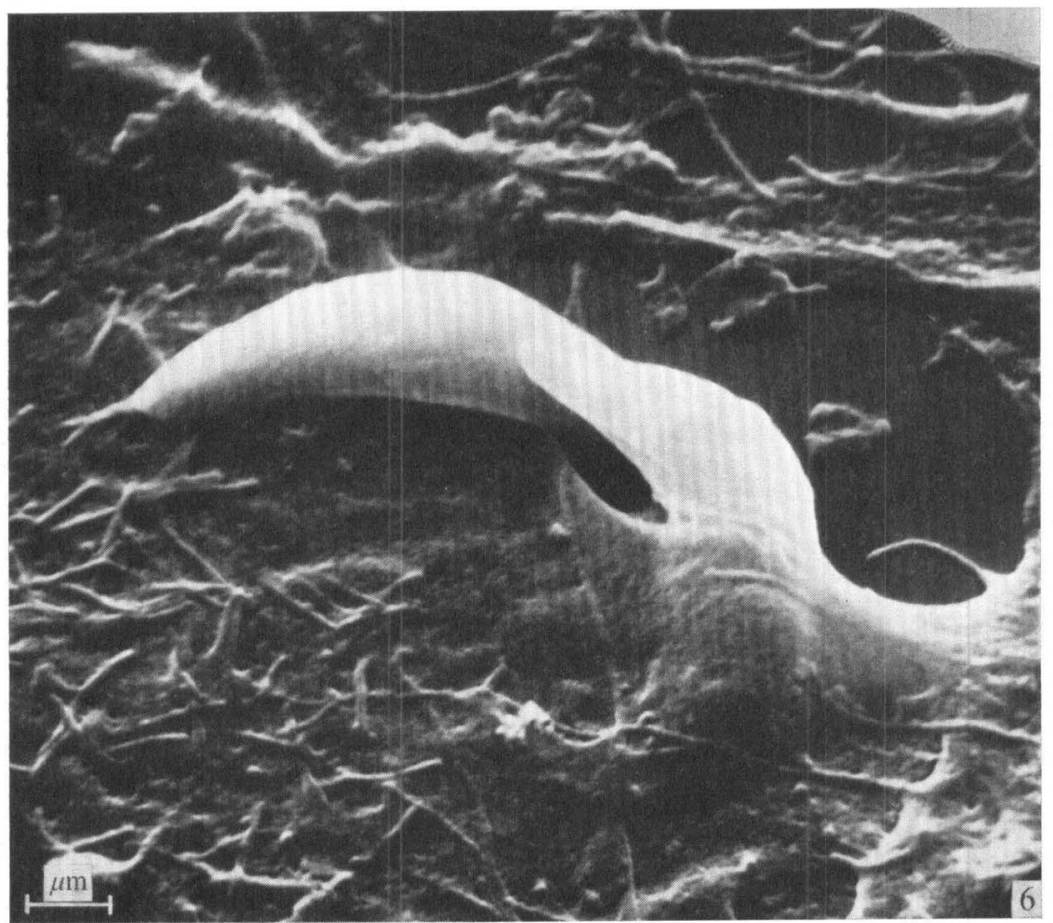

Fig. 6. A trophozoite trapped between the substrate and the cell membrane of an L-cell; this phenomenon is consistent with surface phagocytosis. 


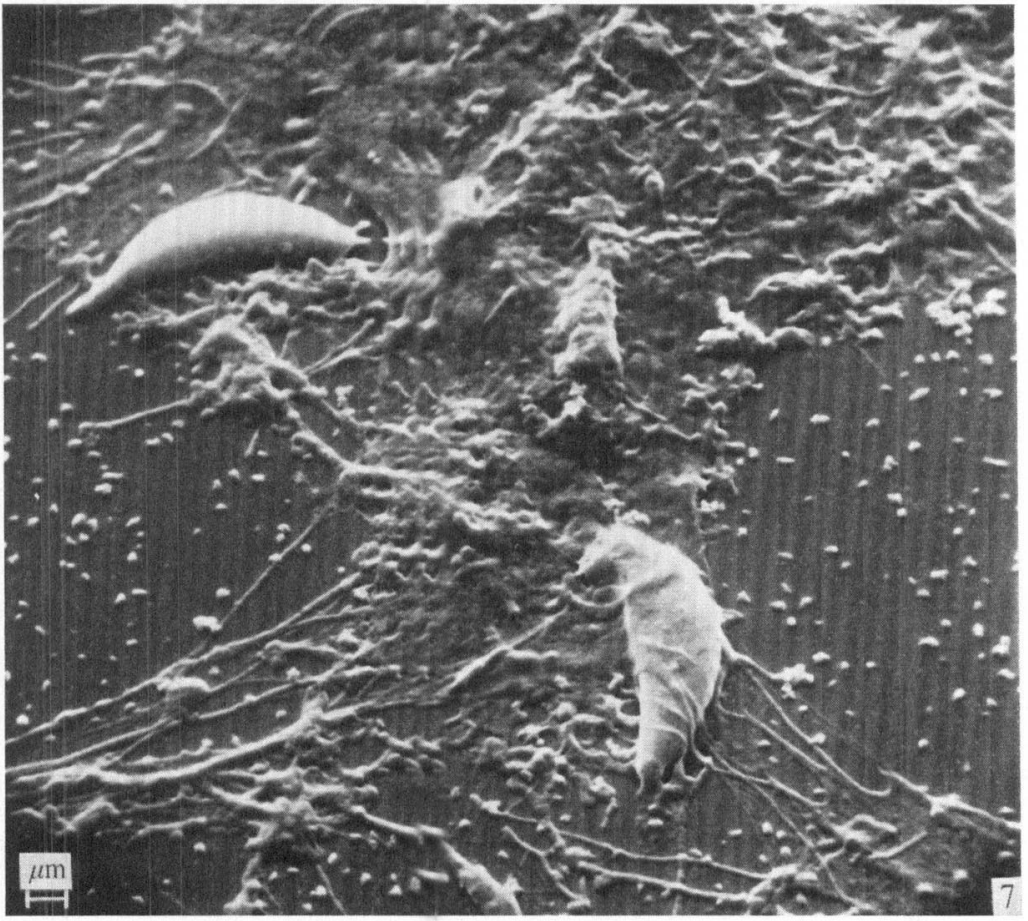

Fig. 7. Attachment of a trophozoite to an L-cell by what appear to be pseudopods of the latter.

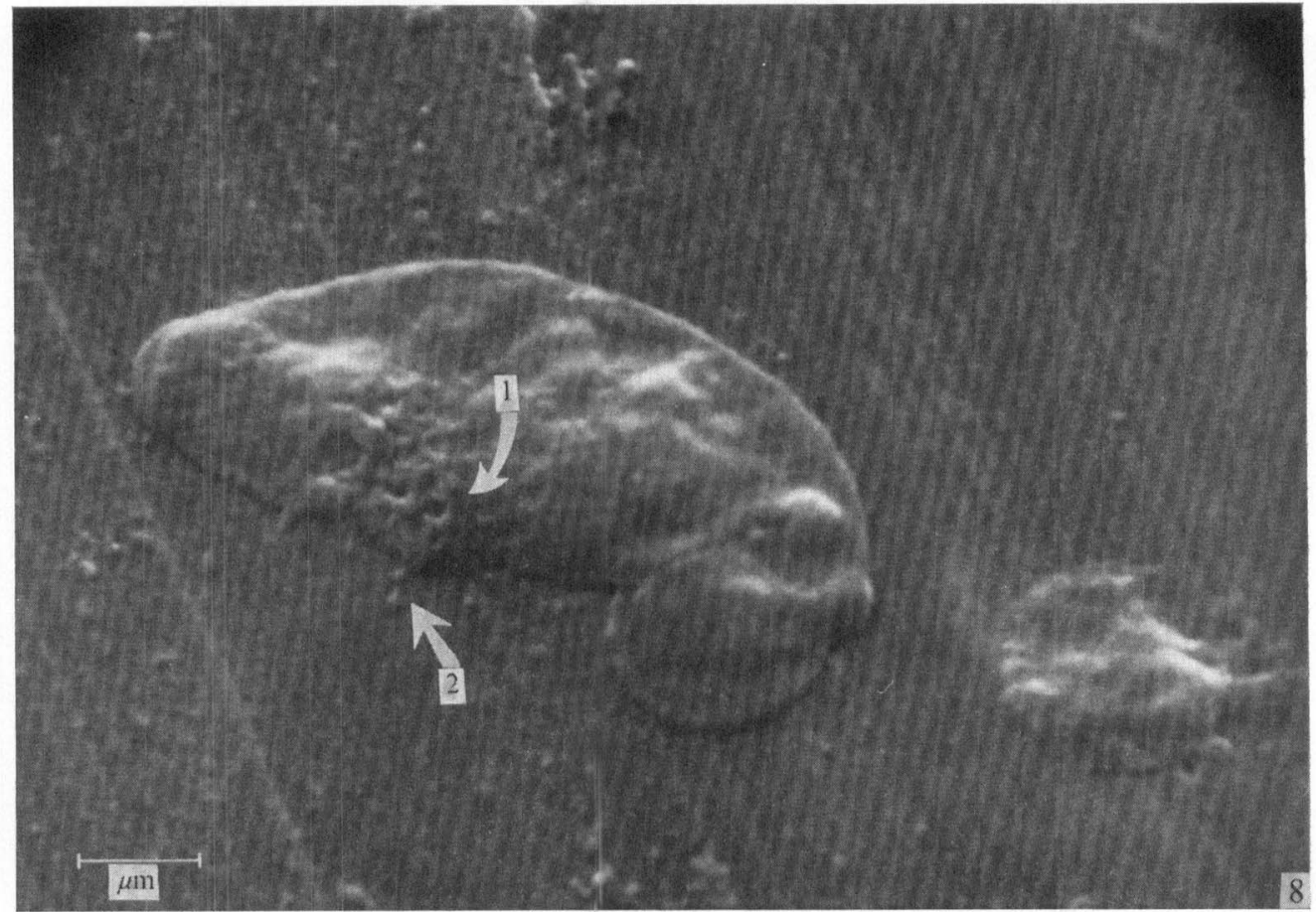

Fig. 8. A trophozoite which has been exposed to accessory factor and antibody for $\mathrm{I}$ h at $37^{\circ} \mathrm{C}$. The organism is collapsed and the surface is coarse. Arrow I demonstrates irregular vacuoles on the surface; arrow 2 points out what appears to be extrusion of cytoplasmic contents. 
surface phagocytosis (Fig. 6); and (iii) attachment of the organism to the cell surface aided by what appeared to be pseudopods (Fig. 7). It would appear that a variety of surfacesurface interactions between Toxoplasma trophozoites and L-cells can occur; active penetration may be merely one or the common end result of several or all attachment phenomena.

A Toxoplasma trophozoite exposed to accessory factor and antibody for $\mathrm{I} \mathrm{h}$ at $37{ }^{\circ} \mathrm{C}$ is illustrated in Fig. 8. The organism is collapsed; the surface is coarse, and irregular vacuoles can be seen (arrow I) as well as what appears to be extrusion of cytoplasmic contents (arrow 2). These findings are consistent with the observations of Lelong \& Desmonts (1952), Gronroos (I959) and Jacobs, Remington, Melton \& Lunde (I959), that antibody results in partial lysis of the organism and renders it unstainable with methylene blue.

\section{DISCUSSION}

The relationship of Toxoplasma gondii trophozoites to mouse peritoneal macrophages and L-cells is of particular interest. Organisms were seen adhering to the surface of macrophages, trapped beneath their cell membrane, or surrounded by pseudopods; these observations suggest that an attachment phase consistent with phagocytosis occurs prior to entry. Although there was some suggestion that the organism does actively penetrate L-cells, the entrapment of organisms by L-cell pseudopodia and the apparent folding of the cell membrane over the parasite are consistent with phagocytosis of Toxoplasma. Pulvertaft, Valentine \& Lane (1954) found that Toxoplasma gained entry into host cells in two different ways, by active penetration and by the process of phagocytosis; the studies reported herein emphasize the latter mechanism and the comment of Pulvertaft et al. (1954) that nonphagocytic cells can act as host cells of the parasite. More recently, phagocytosis of Toxoplasma by cells normally considered non-phagocytic (e.g. HeLa cells and fibroblasts) has been documented by Jones \& Hirsch (1973); this observation substantiates our findings.

Membrane defects and the extrusion of intracellular material observed when trophozoites were exposed to antibody and accessory factor substantiate the concept of Lelong \& Desmonts (1952), that antibody damages the cell membrane with subsequent extrusion of intracellular material. This may render the cells non-stainable with methylene blue and, more importantly, non-viable.

Certain organisms (Fig. 2, 5) appeared to have pores or dimples on their surfaces. These are probably an artifact due to washing prior to fixation, but could represent an external manifestation of endodyogeny or the micropyle (Garnham, Baker \& Bird, 1962; Sheffield \& Melton, I968).

These studies were supported in part by a grant from the National Institutes of Health, AI-047I7, to Dr J. Remington.

\section{REFERENCES}

Feldman, H. A. (1956). The relationship of Toxoplasma antibody activator to the serum-properdine system. Annals New York Academy of Sciences, 66, 263-267.

Garnham, P. C. C., BaKer, J. R. \& Bird, R. G. (1962). Fine structure of cystic form of Toxoplasma gondii. British Medical Journal I, 83-84.

Gronroos, P. (1959). Some remarks on the mechanism of the dye test. In Human Toxoplasmosis, Proceedings of the Conference on Clinical Aspects and Diagnostic Problems of Toxoplasmosis in Pediatrics. Edited by J. Chr. Siim. Baltimore: Williams \& Wilkins.

Gustafson, P. V., Agar, H. D. \& Cramer, D. S. (1954). An electron microscope study of Toxoplasma gondii. American Journal of Tropical Medicine 3. 1008-I02I. 
Jacobs, L., Remington, J. S., Melton, M. L. \& Lunde, M. N. (1959). The relationship of toxoplasma dye test and neutralization antibodies. Journal of Parasitology (Suppl.) 45, 52.

Jones, T. C. \& HiRSCH, J. G. (1973). Survival of $T$. gondii within phagocytic vacuoles: Evidence of absence of lysosomal fusion. Clinical Investigation (Abstract) (in the press).

KLAiner, A. S. \& BETSCH, C. J. (1970). Scanning beam electron microscopy of selected microorganisms. Journal of Infectious Diseases 121, 339-343.

Lelong, M. \& Desmonts, G. (1952). Sur la nature du phenomène de Sabin et Feldman. Compres rendus des séances de la Société de biologie 146, 207-209.

Nicolle, C. \& ManceauX, L. (1908). Sur une infection à corps de Leishman (ou organismes voisins) du gondi. Compte rendu hebdomadaire des séances de l'Académie des sciences 147, 763-766.

Pulvertaft, R. J. V., Valentine, J. C. \& LANe, W. F. (I954). The behaviour of Toxoplasma gondii on serum agar culture. Parasitology 44, 478-484.

Remington, J. S., Bloomfield, M. M., Russell, E. \& Robinson, W. S. (i970). The RNA of Toxoplasma gondii. Proceedings of the Society of Experimental Biology and Medicine 133, 623-626.

Ruskin, J., McIntosh, J. \& Remington, I. S. (1969). Studies on the mechanisms of resistance to phylogenetically diverse intracellular organisms. Journal of Immunology 103. 252-259.

Sheffield, H. G. \& Melton, M. L. (1968). The fine structure and reproduction of Toxoplasma gondii Journal of Parasitology 54, 209-226. 